Pesq. Vet. Bras. 36(10):935-938, outubro 2016 DOI: 10.1590/S0100-736X2016001000003

\title{
Intoxicação experimental por folhas de Crotalaria pallida (mucronata) em ovinos ${ }^{1}$
}

INDEX TERMS: Poisonous plants, animal pathology, Crotalaria mucronata, plant poisoning, sheep.

RESUMO.- Descrevem-se o quadro clínico, patológico e o potencial tóxico das folhas verdes de Crotalaria pallida em ovinos. Para o experimento folhas verdes de C. pallida foram coletadas no município de São João do Sul em Santa Catarina e administradas por via oral para seis ovinos adultos, em doses únicas de 40,20,10,5,2,5 e 2,5g/kg, e para dois ovinos, em doses diárias de 0,63 e $1,25 \mathrm{~g} / \mathrm{kg}$ durante 30 dias. Reproduziu-se a intoxicação com doses letais a

\footnotetext{
${ }^{1}$ Recebido em 25 de fevereiro de 2016.

Aceito para publicação em 3 de julho de 2016.

Parte da Tese de Doutorado da primeira autora, concluída no ano de 2015 na Universidade do Estado de Santa Cantarina.

${ }^{2}$ Laboratório de Patologia Animal, Centro de Ciências Agroveterinárias (CAV), Universidade do Estado de Santa Catarina (UDESC). Av. Luiz de Camões 2090, Bairro Conta Dinheiro, Lages, SC 88520-000, Brasil. *Autor para correspondência: $\underline{\text { a2ag@cav.udesc.br }}$
}

partir de 2,5g/kg. Um dos ovinos que recebeu a dose única de $2,5 \mathrm{~g} / \mathrm{kg}$ e os que receberam as doses diárias, não adoeceram. Todos os ovinos que apresentaram sinais clínicos morreram entre 13 e 22 horas após a administração das folhas. Sinais clínicos leves como fezes pastosas, inquietação e aumento das frequências cardíaca e respiratória tiveram início cerca em 11 horas após a ingestão da planta. Minutos antes da morte observaram-se dispneia intensa com respiração abdominal pronunciada. As principais lesões macroscópicas foram restritas à cavidade torácica, como hidrotórax e edema pulmonar acentuado. 0 exame microscópico revelou no pulmão, edema acentuado e difuso na superfície pleural, nos espaços interlobulares e ao redor das artérias peribronquiais e peribronquiolares. Edema multifocal foi observado no interior de alvéolos e ao redor de brônquios e bronquíolos, além de leve infiltrado neutro- 
fílico multifocal. 0 quadro clínico-patológico da intoxicação experimental foi similar ao observado na intoxicação espontânea e caracterizou-se por edema iulmonar acentuado e morte logo após o início dos sinais clínicos.

TERMOS DE INDEXAÇÃO: Plantas tóxicas, patologia animal, Crotalaria mucronata, intoxicação por plantas, ovinos.

\section{INTRODUÇÃO}

Na região do litoral sul do Estado de Santa Catarina diagnosticou-se um surto com alta mortalidade em ovinos, que ocorreu entre os meses de janeiro e fevereiro de 2012, após os animais permanecerem em uma área com grande quantidade de Crotalaria pallida. De um total de 186 ovinos adultos da raça Texel, 23 morreram sendo 12 em um único dia, logo após a roçada da Crotalaria que existia em grande quantidade junto ao pasto. Os animais foram encontrados mortos sem evidenciação de sinais clínicos pelo produtor. Na macroscopia observaram-se hidrotórax, edema pulmonar acentuado na superfície pleural e grande quantidade de espuma no interior de brônquios e traquéia. A doença foi reproduzida através da administração de folhas verdes de C. pallida para um ovino adulto em dose única de $40 \mathrm{~g} /$ $\mathrm{kg}$ (Borelli et al. 2015).

No Brasil, há relato de intoxicação espontânea por Crotalaria pallida em bovinos, no estado de Minas Gerais. Neste surto morreram 12 animais após receberem ração contaminada com sementes de Crotalaria que adicionalmente ingeriram a planta no quintal de uma casa abandonada (Lemos et al. 1997). 0 período de evolução foi de 15 a 30 dias. Na necropsia havia lesões pulmonares e hepáticas. 0 exame microscópico revelou, nos pulmões espessamento difuso das paredes alveolares devido à proliferação dos pneumócitos tipo II e de fibroblastos. Em apenas um bovino foram observadas lesões hepáticas caracterizadas por necrose centro-lobular e moderada fibrose periportal (Lemos et al. 1997).

Experimentalmente para esta mesma espécie, folhas verdes de C. pallida causaram intoxicação nas doses únicas de 60 e de $80 \mathrm{~g} / \mathrm{kg}$. Os sinais clínicos mais evidentes foram tremores musculares e na necropsia apenas um bovino que morreu com a dose de $25 \mathrm{~g} / \mathrm{kg}$, apresentou hidrotórax e edema pulmonar acentuados. Os animais morreram entre 16 e 68 horas após a administração da planta (Tokarnia \& Döbereiner 1982).

Em outro estudo, sementes moídas de $C$. pallida, foram administradas para bovinos em doses diárias de 5, 7,5 e $10 \mathrm{~g} / \mathrm{kg}$ durante 47 a 61 dias. Os animais apresentaram sinais clínicos entre 47 e 80 dias após o início da administração e morte entre 3 horas e 5 dias após o início da sitomatologia. Os principais sinais foram pulso venoso positivo da veia jugular, respiração abdominal, taquicardia, fezes ressequidas, edema submandibular e fraqueza. Os achados de necropsia foram palidez pulmonar, hidropercárdio, hidrotórax, hidroperitôneo, edema de mesentério, aumento da consistência hepática, dilatação de ventrículo direito e edema da parede ruminal. 0 exame histológico revelou, no pulmão, espessamento das paredes alveolares e da parede das arteríolas, com diminuição da luz e fibrose periarteriolar (Boghossian et al. 2007).
Os objetivos deste estudo foram determinar através de experimentos a dose tóxica, possível efeito acumulativo e caracterizar os achados clínico-patológicos da intoxicação por C. pallida em ovinos.

\section{MATERIAL E MÉTODOS}

O estudo foi realizado nas dependências do Laboratório de Patologia Animal, da Universidade do Estado de Santa Catarina. Para a experimentação foram colhidas folhas verdes de Crotalaria pallida (Fig.1), na propriedade onde ocorreu o surto. As folhas foram mantidas em câmara fria e posteriormente administradas por via oral em dose única de 40,20,10,5, 2,5 e 2,5g/ $\mathrm{kg}$, para seis ovinos adultos; para dois outros ovinos foram administradas doses diárias de 0,63 e 1,25g/kg durante 30 dias. Os ovinos eram provenientes de propriedade livre de C. pallida. Durante o experimento os ovinos foram mantidos em baias de alvenaria e alimentados com capim quicuio (Pennisetum clandestinum), azevém (Lolium multiflorum) e água ad libitum. Os animais foram pesados e submetidos a exames clínicos antes e repetidas vezes após a administração da planta, sendo avaliados a frequência respiratória e cardíaca, movimentos ruminais, temperatura retal, além do comportamento. Os ovinos que morreram foram necropsiados e amostras de tecidos de pulmão, coração, rumem, omaso, abomaso, intestino, fígado, rim, baço, linfonodo e sistema nervoso central foram colhidas e fixadas em formalina a $10 \%$, para exame histológico. 0 material foi processado rotineiramente, corado pela técnica de Hematoxilina-Eosina (HE) (Prophet et al. 1992) e avaliado em microscópio óptico. 0 projeto de pesquisa foi aprovado pelo comitê de ética de Experimentação animal da Universidade do Estado de Santa Catarina (CETEA/UDESC) sob o Protocolo 1.13 .12 em 2012.

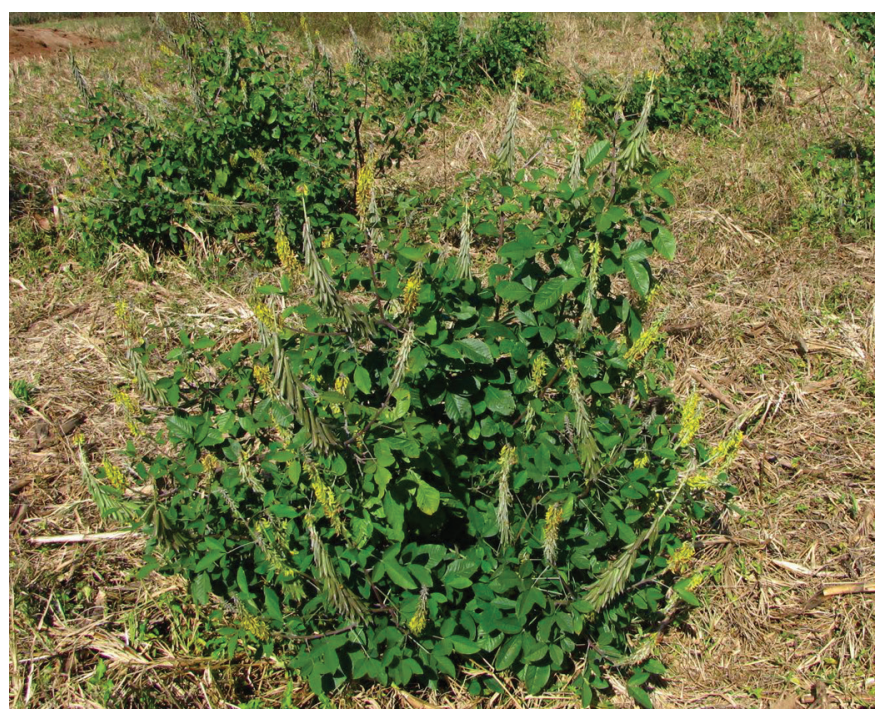

Fig.1. Crotalaria pallida no Município de São João do Sul, SC.

\section{RESULTADOS}

Na intoxicação experimental, os Ovinos 1, 2, 3, 4 e 6 morreram entre 13 e 22 horas após a administração da planta. Nestes animais os sinais clínicos foram semelhantes e iniciavam com inquietação; os animais deitavam e levantavam várias vezes. Observaram-se fezes pastosas, diminuição do apetite, respiração abdominal e aumento das frequências cardíaca e respiratória. Minutos antes da morte, a respiração abdominal tornava-se pronunciada com dispneia, caracterizada por movimentação acentuada das narinas e 
Quadro 1. Resultados da intoxicação experimental por Crotalaria pallida em ovinos

\begin{tabular}{ccccc}
\hline Ovino & $\begin{array}{c}\text { Peso animal } \\
(\mathrm{kg})\end{array}$ & $\begin{array}{c}\text { Dose }(\mathrm{g} / \mathrm{kg}) / \\
\mathrm{n} \text { - } \text { administrações }\end{array}$ & $\begin{array}{c}\text { Início dos sinais } \\
\text { clínicos(h) }\end{array}$ & $\begin{array}{c}\text { Morte após } \\
\text { administração } \\
\text { da planta (h) }\end{array}$ \\
\hline 1 & 53 & $40 / 1$ & 12 & 15 \\
2 & 33 & $20 / 1$ & 14 & 17 \\
3 & 48 & $10 / 1$ & 11 & 13 \\
4 & 53 & $5 / 1$ & 17 & 18 \\
5 & 55 & $2,5 / 1$ & Não adoeceu & - \\
6 & 52 & $2,5 / 1$ & 21 & 22 \\
7 & 48 & $1,25 / 30$ & Não adoeceu & - \\
8 & 55 & $0,63 / 30$ & Não adoeceu & -
\end{tabular}

abertura da boca na tentativa de respirar. Todos os animais que adoeceram morreram em aproximadamente 10 minutos após o início da dispneia. 0 delineamento experimental está representado no Quadro 1.

Macroscopicamente as mucosas estavam cianóticas, havia hidrotórax com aproximadamente um litro de líquido translúcido, hidropericardio, pulmão volumoso não colabado, pesado e brilhante com edema acentuado de consistência gelatinosa, subpleural (Fig.2), interlobular e ao redor das artérias. A coloração do pulmão variou entre pálida ou com áreas vermelho-escuras. Na traqueia e brônquios havia grande quantidade de espuma. 0 exame microscópico revelou no pulmão, edema acentuado e difuso na superfície pleural (Fig.3A), nos espaços interlobulares e ao redor das artérias peribronquiais e peribronquiolares (Fig.3B). Edema multifocal foi verificado no interior de alvéolos e ao redor de brônquios e bronquíolos, além de leve infiltrado inflamatório neutrofílico multifocal. Nos demais órgãos não foram observadas lesões. Os Ovinos 5, 7 e 8 que receberam, respectivamente, dose única de $2,5 \mathrm{~g} / \mathrm{kg}$ e doses diárias de 0,63 e 1,25g/kg por 30 dias não adoeceram.

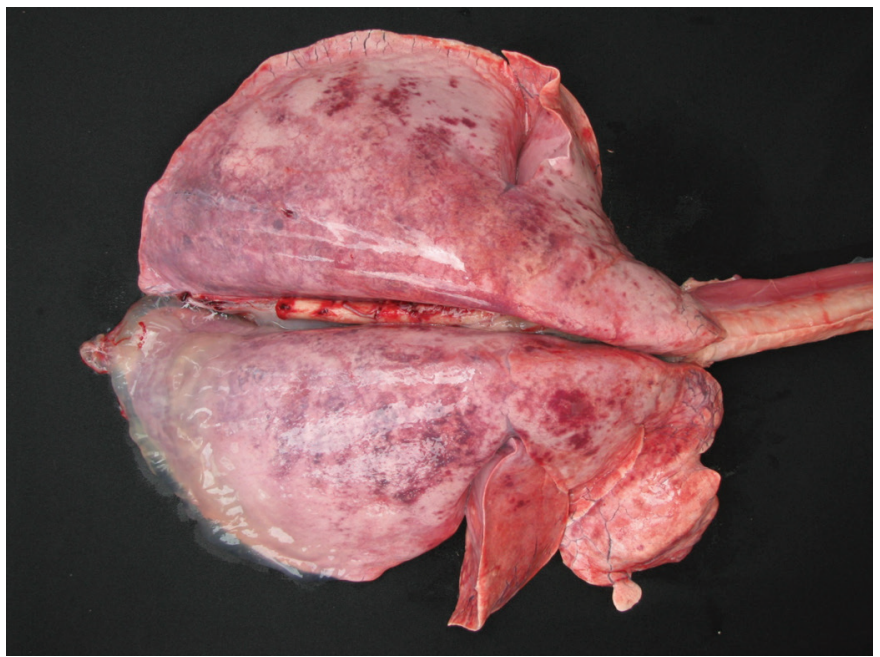

Fig.2. Intoxicação experimental por Crotalaria pallida em ovinos. Superfície dorsal dos pulmões, não-colabados, com edema subpleural acentuado e áreas vermelho-escuras.

\section{DISCUSSÃO}

Os ovinos apresentaram alta sensibilidade à ingestão de folhas verdes de Crotalaria pallida, pois doses únicas a partir de $2,5 \mathrm{a} 40 \mathrm{~g} / \mathrm{kg}$ provocaram a morte dos animais em um

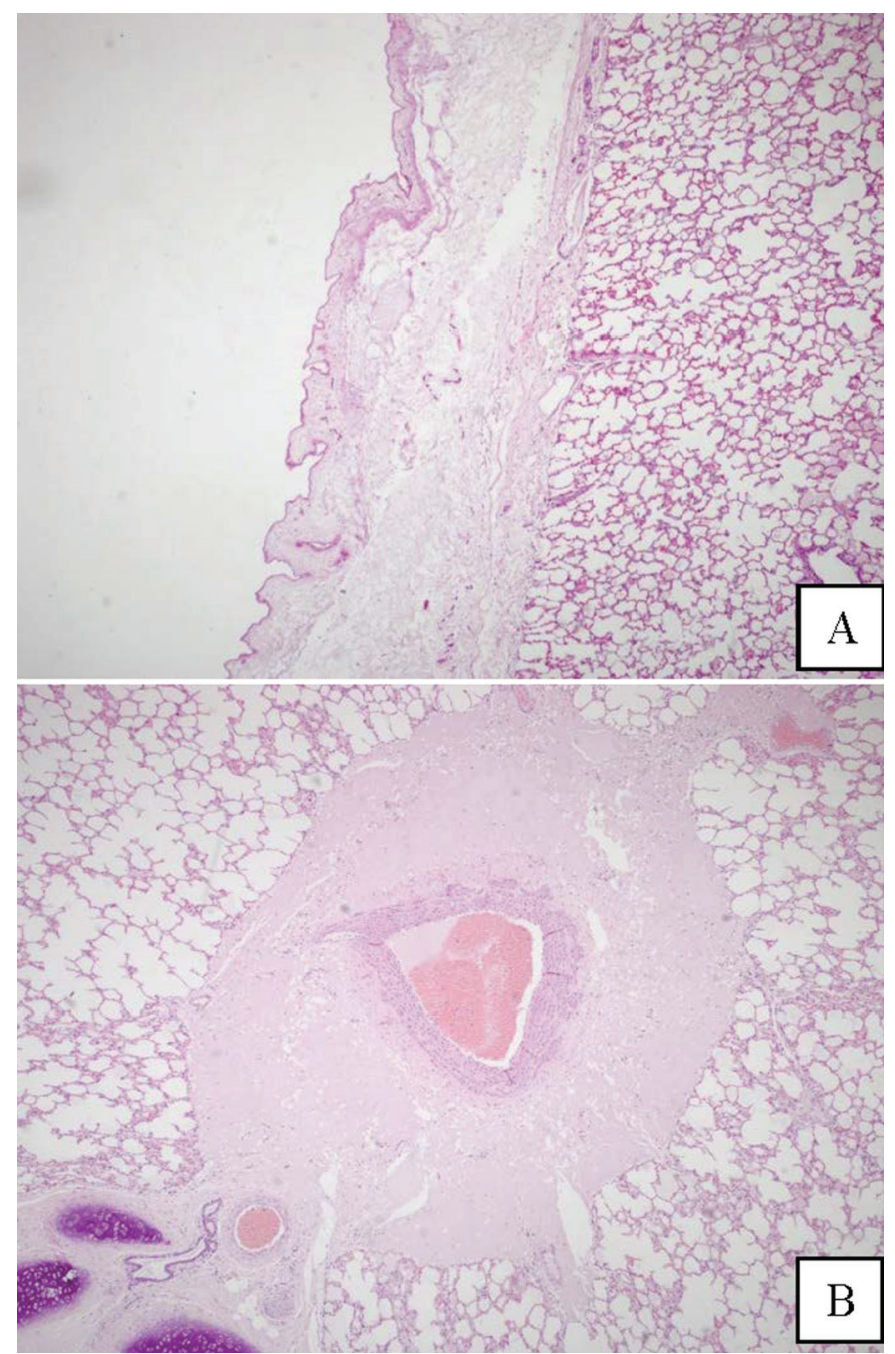

Fig.3. Intoxicação experimental por Crotalaria pallida em ovinos. (A) Edema subpleural (Ovino 4). HE, obj.5x. (B) Edema acentuado ao redor da artéria peribronquial (Ovino 4). HE, obj.10x.

intervalo de 13 a 22 horas após o fornecimento da planta. No experimento realizado por Laws (1968) as doses letais para os ovinos foram próximas a $10 \mathrm{~g} / \mathrm{kg}$. Em contrapartida, Tokarnia \& Döbereiner (1982) verificaram em bovinos, mortes com doses únicas a partir de $25 \mathrm{~g} / \mathrm{kg}$.

Doses diárias de 0,63 e 1,25g/kg de C. pallida para os ovinos não ocasionaram efeito acumulativo, já que os animais que receberam a planta durante 30 dias, não adoeceram. Estes resultados foram compatíveis com os experimentos realizados em bovinos por Tokarnia \& Döbereiner (1982), pela administração de folhas verdes de C. pallida nas doses de 2,5, 5 e 10g/kg durante 120, 60 e 30 dias, respectivamente, pois não manifestaram sinais clínicos. Por outro lado, sementes moídas dessa planta administradas também para bovinos em doses diárias de $5,7,5$ e $10 \mathrm{~g} / \mathrm{kg}$ durante 47 a 61 dias, causaram sinais clínicos entre 47 e 80 dias após o início da administração (Boghossian et al. 2007).

Edema pulmonar acentuado foi a principal lesão macroscópica verificada nos ovinos deste estudo. Na microscopia a distribuição e a intensidade do edema foram iguais 
em todos os pulmões avaliados, e era muito intenso ao redor das artérias peribronquiais e peribronquiolares, no espaço subpleural e interlobular. Estes achados contribuem significativamente para o diagnóstico definitivo. As lesões microscópicas pulmonares observadas nos ovinos são diferentes das descritas na intoxicação por C. pallida em bovinos, nos quais havia espessamento das paredes alveolares e da parede das arteríolas, com diminuição da luz e fibrose periarteriolar (Boghossian et al. 2007). Esta diferença pode estar relacionada ao período de evolução da doença, uma vez que em ovinos, a evolução rápida não permitiu o desenvolvimento de alterações crônicas nos pulmões.

Outras espécies de Crotalaria também foram associadas a alterações pulmonares, como a $C$. juncea em equinos, em que observam-se alveolite fibrosante difusa, com espessamento dos septos alveolares, formação de membrana hialina e epitelização alveolar (Nobre et al. 1994). Em suínos, C. spectabilis causa edema pulmonar interlobular e lesão hepática aguda concomitante (Ubiali et al. 2011).

A toxicidade das plantas do gênero Crotalaria tem sido atribuída a grande quantidade de monocrotalina, que é um alcalóide pirrolizidínico (AP). A metabolização dos APs ocorre principalmente no fígado e caracteriza-se pela formação de compostos pirrólicos que são, na maioria das vezes, catalisados pelo sistema enzimático citocromo P450 (Cheeke 1994). Os ésteres pirrólicos são agentes alquilantes que inibem a mitose celular no fígado, mas a síntese de DNA permanece contínua. Eles também induzem à necrose e perda de hepatócitos, que posteriormente são substituídos por tecido fibroso (Petry et al. 1984). Apesar de não se saber exatamente porque em alguns animais ocorre somente lesão pulmonar, Kim et al. (1993), constataram que os pulmões também produzem pirróis por conter enzimas do sistema citocromo P450. 0 mecanismo de formação do edema pulmonar não foi esclarecido. No entanto a monocrotalina extraída de espécies de Crotalaria é utilizada com frequência como modelo para reproduzir hipertensão pulmonar em animais de laboratório (Lee et al. 2005).

\section{CONCLUSÕES}

As folhas verdes de Crotalaria pallida quando ingeridas por ovinos, em doses únicas apatir de $2,5 \mathrm{~g} / \mathrm{kg}$ produzem doença respiratória aguda e o principal sinal clínico é dispneia grave, seguida de morte em alguns minutos após o início dos sinais clínicos.
As lesões macroscópicas da intoxicação por C. pallida caracterizam-se por hidrotorax e edema pulmonar.

No exame microscópico, observou-se edema pulmonar marcadamente acentuado ao redor das artérias peribronquiais e peribronquíolares, no espaço subpleural e interlobular.

Doses diárias de 0,63 e 1,25g/kg de folhas verdes de Crotalaria pallida administradas por 30 dias, não causaram efeito acumulativo em ovinos.

\section{REFERÊNCIAS}

Boghossian M.R., Peixoto P.V., Brito M.F. \& Tokarnia C.H. 2007. Aspectos clinico-patológicos da intoxicação experimental pelas sementes de Crotalaria mucronata (Fabaceae) em bovinos. Pesq. Vet. Bras. 27(4):149156.

Borelli V. 2015. Intoxicação espontânea e experimental por folhas verdes de Crotallaria (mucronata) pallida em ovinos. Tese de Doutorado. Programa de Pós-Graduação em Ciência Animal, Universidade do Estado de Santa Catarina, Centro de Ciências Agroveteinárias, Lages, SC. 53p.

Cheeke P.R. 1994. A review of the functional and evolutionary roles of the liver in the detoxification of poisonous plants, with special reference to pirrolizidine alkaloids. Vet. Human Toxicol. 36:240-247.

Kim H.Y., Stermitz F.R., Molyneaux R.J., Wilson D.W., Taylor D. \& Coulombe R.A. Jr. 1993. Structural influences on pyrrolizidine alkaloid-induced cytopathology. Toxicol. Appl. Pharmacol. 122:61-69.

Laws L. 1968. Toxicity of Crotalaria mucronata to sheep. Aust. Vet. J. 44(10):453-455.

Lee Y.S., Bryun J., Kim J.A., Lee J.S., Kim K.L., Suh Y.L., Kim J. M., Jang H.S., Lee J.Y., Shin I.S., Suh W., Jeon E.S. \& Kim D.K. 2005. Monocrotaline-induced pulmonary hypertension correlates with upregulation of connective tissue growth factor expression in the lung. Exp. Mol. Med. 37:27-35.

Lemos R.A.A., Dutra I.S., Souza G.F., Nakazato L. \& Barros C.S.L. 1997. Intoxicação espontânea por Crotalaria mucronata em bovinos em Minas Gerais. Arqs Inst. Biológico, São Paulo, 64(Supl.). 46p.

Nobre D., Dagli M.L.Z. \& Haraguchi M. 1994. Crotalaria juncea intoxication in horses. Vet. Human Toxicol. 36:445-448.

Petry T.W., Bowden G.T., Huxtable R.J. \& Sipes I.G. 1984. Characterization of hepatic DNA damage induced in rats by the pyrrolizidine alkaloid monocrotaline. Cancer Res. 44:1505-1509.

Prophet E.B., Mills B., Arrington J.B. \& Sobin L.H. 1992. Laboratory Methods in Histotechnology. American Registry of Pathology, Armed Forces Institute of Pathology, Washington, DC. 274p.

Tokarnia C.H. \& Döbereiner J. 1982. Intoxicação experimental por Crotalaria mucronata (Leg. Papilionoideae) em bovinos. Pesq. Vet. Bras. 2(2):77-85.

Ubiali D.G., Boabaid F.M., Borges N.A., Caldeira F.H.B., Lodi L.R., Pescador C.A., Souza M.A. \& Colodel E.M. 2011. Intoxicação aguda com sementes de Crotalaria spectabilis (Leg. Papilionoideae) em suínos. Pesq. Vet. Bras. 31(4):313-318. 